\title{
Jeff Wall and the Object of Photography
}

\author{
Dr. Gerry Coulter \\ Bishop’s University, Sherbrooke, Canada
}

\begin{abstract}
This paper discusses the work of the Canadian artist Jeff Wall who uses photographic technology to make and display his work. It argues that Wall is among the world's leading artists and that the resulting works, while made with photographic technology, are not photography. Indeed, Jeff Wall is an anti-photographer whose work demonstrates the artist's need to control the object of photography. While not arguing for an object-based aesthetics this paper makes the case for allowing the object (which seizes the attention of the photographer) at least some role in the process of creating the final image. It is precisely in his need to dominate and control the object through his process that Wall establishes himself as an important artist, but he is not a photographer.
\end{abstract}

Keywords:Photography, Art, Meaning, Image, Aesthetics

\section{Introduction}

"The spontaneous is the most beautiful thing that can appear in a picture, but nothing in art appears less spontaneously than that” (Ross, 2002, p. 555).

"We have to escape truth, and to escape truth you must not trust the subject, you have to leave matters to the object and its strange attraction, the world and its definitive uncertainty” (Baudrillard, 2001, p. 17).

Canadian artist Jeff Wall"s work is among the most interesting to achieve prominent status in the international art world in the past quarter century. It is especially useful for the role it can play in current efforts to understand the meaning of photography. Wall considers himself a "photographer" and his work "photography". Everyone writing about him in the art world, and curating his works in galleries and museums, recognizes Wall as a "photographer". In 2002 when he won the very prestigious Hasselblad Foundation International Award it was for "photography". Indeed, many of Wall's images are considered to be icons of contemporary photography.

In this essay the writer argues that while Wall does use a camera to record images that eventually become the transparencies spread over his "light boxes", his practice is not photography. Indeed, Wall's relation to the object is the reverse of photography to the extent that people can call his use of the camera (and related digital technologies), anti-photography. While Wall has made some documentary photographs (such as The Bridge (1980), The Old Prison (1987), his Diagonal Compositions (of the 1990s), the vast majority of the work he is

Gerry Coulter, Full Professor and Past Chairperson, Bishop's University.

Correspondence concerning this article should be addressed to 2600 College Street,Sherbrooke, Quebec,Canada J1M 0C8.

Email: gcoulter@ubishops.ca. 
famous for is not photography at all. These and most of Wall's individual works are best accessed on the internet by entering his name and the title of the work.

\section{The Object of Photography}

What is a photograph? What happens when a photograph is taken? When taking a photograph of a person, a bridge, a building, a tree, a lamp etc. what is taking place? Is it simply the act of a subject "taking" the image of an object? Does the writer as the subject holding the camera possess all the power in a subject-object relationship? The writer does not believe that he does. Perhaps, the writer holds no power at all other than the will to close the shutter after the object has seized his attention. In any event, if he ever felt a need to seize the object, he has surrendered it to the objective pleasures of taking photographic images. This pleasure has increased as he has learned to recognize the power of the object in the photographic event. The best thing that can happen to me as a subject holding a camera is to be "seduced by the object" and acknowledge that he is the prey of appearances (Baudrillard, 1990, p. 83).

People like to think that photography allows them to see the object from the point of view of the subject, but photography also allows them to see the subject from the vantage point of the object - for they never know reality, merely the appearances behind which it hides. The writer's position should not be confused with a simple inversion to an object-based aesthetics. What he does wish to stress is that in photography the object is also the site of the disappearance of the subject — hence the subject, while commanding the recording process, must give up the notion of holding all the power. It is precisely this sacrifice that is necessary to the photographic act and it is the sacrifice that Wall resists in his "cinematographic photographs".

The writer's understanding of photography is based on openness to the notion that the object too has some power in the presence of the photographer subject. Indeed, as the writer has come to experience photography, it is in the effort to excert power over the object that photography ends and they enter into some kind of anti-photography — the world of art and aesthetics — a place where we no longer "take" the image of the object that has seized them, but where, in attempting to seize the object, command and control it under a hegemonic subjective gaze, they move from "taking" images to "making" images. Here the role of digital processing, e.g., photoshop appears and photography ends where art making begins (Jeff Wall's practice in particular). The writer's understanding of photographic practice has far reaching implications for how viewing the work of people who travel under the name of "photographer".

It is a very difficult thing for a mind labouring under the weight of Western humanism and its accompanying metaphysics and epistemology to comprehend that there are instances when the subject is not completely in control of things. This is not to fully take the side of the object, merely to recognize that photographic technology destabilizes people's understanding of subject and object. Popular wisdom and dominant photographic theory assert that it is the subject which selects, edits, and frames the object into the photograph. These notions are so entrenched as to have become "common-sense assumptions" when discussing the medium. Yet people are far enough into an ironic reading of the world to know that as much as we read a book or watch television, and it is also the book that reads us, or the television that watches them. Why then do people not also seek to understand that it is the object (of photography) that, while they attempt to seize it, also seizes them?

The much less interesting (and dominant) theory of photography allows the subject to believe that she or he is shrewder than the object. The photographic theory that the writer asserts understands the object as lying in 
wait for the subject. The great benefit of this approach is that it allows people to understand photography as something random and less predictable (more object based) than the world of art and aesthetics have thus far allowed. The writer's view also allows them to delve into the subtleties of an artist like Wall's practice while developing a more sophisticated understanding of the role of photography in artistic practice.

The dominant theory of subject dominance is the easy solution to some very complex problems posed by the introduction of photography over a century and a half ago. It has proven to be an indispensable weapon in the war between art and photography in which art and aesthetics have sought, and perpetrated to a good extent, a hostile takeover of photography. Jeff Wall and other "art-photographers", whatever their intentions, are vitally important in this takeover. Yet, if people challenge their biases about subject and object, they may find a place for photography where it belongs, outside of the world of art and aesthetics where the object can be understood as something (at least somewhat) beyond the control of the subject — the viewpoint of the subject's disappearance. The writer's view of photography allows the subject photographer to conceive of him/herself as the dominant actor in the exchange with the photographic object but under conditions where people at least acknowledge the power of the object to seize the attention of the photographer. After all, why did they choose "this house" among all the others in the city to photograph when they know nothing of its history or occupants more than that of any other house in town? Why did it seize our attention when all the others did not? Here they may consider the power of photography's objects.

The object is a very strange attractor (Baudrillard, 1997, p. 14). It is precisely this strange attraction that Wall foregoes in the making of his images wherein the subjective vision does not merely dominate, but seeks maximal control and mastery through orchestration, direction, acting, meticulous arrangement, and ultimately digitalization. Now to be fair to Jeff Wall, whose work the writer finds very interesting (the writer simply does not believe they should call it photography), all images are simulation. For the writer however, Wall takes people a step beyond the point where this simulation may still be recognized as photography.

Rather than allowing that he is seized in any way by the object, Wall to the contrary, seizes the object by the throat in his painstaking efforts to command the photographic scene and its production into one of his images for art galleries. Jeff Wall's images are not those of the world, but of his own very creative mind adding layers of subjective interpretation to that world. Light, the very essence of photography, even in his outdoor scenes is artificial. Here, photo-graphy (the writing of light) is reduced to artificiality for a subjective effect. Photography is traded for art and aesthetic effect in such an exchange. Once again people are far from photography here understood as the pure reflex to take pictures - that inversion of vision that allows the object to seize them. It is precisely the desire to create the scene of the photograph, this stage-setting, where art and aesthetics dominate the object of photography.

Wall then is one of the "aestheticizers" of photography, arranging and rearranging every minute detail of the image people see emerge from his laboratory. As such, Wall's images stand against the very technical essence of what photography is - but photography comes from a different place, a place beyond the strictures of imposed aesthetics.

\section{Jeff Wall's Anti-photography}

Jeff Wall provides people with some of the most intriguing of the images that they encounter in their image polluted world. In doing so he may lay claim to be someone who has played a very significant role in establishing images derived from a photographic camera as a contemporary art form. But his works are not 
photographs - he is a recorder of the cinematographic scenes he meticulously constructs, often taking weeks or months and hundreds of photographic images, actors, staged scenes, and digitalization to achieve.

Wall has also crafted the term "cinematographic photograph" to convey some sense of his process and perhaps his own discomfort with the word "photography". But even here the term is deceptive as Wall's cinematographic transparencies that people see in galleries are anything but photographs as the writer understands the practice. There is no better example of this than Wall's A Sudden Gust of Wind [after Hokusai] (1993) [Tate Gallery, London]. To call this image a photograph, even a "cinematographic photograph" is to stretch the definition of photography beyond credulity. Wall has used computers and digitalization to manipulate many of his images such as this one. In reply to Turner's fear that photography would lead to the death of painting, Wall gives people images that participate in the death of photography via the effects of traditional painting. This digital montage, like several others he has created, draws on the fictional character of historical painting in making this image out of over 100 individual photographs.

This anti-photograph makes reference to a print by Katsushika Hokusai bringing it to life in a farmer's field outside of Vancouver. Actors participated in the production of this cinematographic scene. This highly interesting image, steeped in the context of art history (Wall is an art historian by training), is the antithesis of photography and its ability to capture the singular moment in time. Ironically, what people are given here is an image that has taken over a year to script, produce, direct, and digitalize of a singular instant in time. The result is an interesting work of art, but it is not photography — this anti-photograph can only dream of photography.

Wall's The Giant (1992) [private collection] is a work of masterful preparation, planning, and digital manipulation. It is an imaginary scene brought to life as an image of technical invention — image making as an electronic art. To make this computer generated image, Wall digitally assembled shots taken in a library with those of a model standing in a scaled down set. The effect is of a giant standing on the staircase surrounded by Lilliputian library users (the couple descending the staircase at right). This is a kind of surrealism that can originate in a photograph but the end result is an object of the subjective imagination - the object in the world plays no active role here and hence this image is far from a photograph.

Wall's A View from an Apartment (2004-2005) [private collection] is an image made in an apartment that was rented for the making of this image to take place. This room with a view is the product of elaborate direction. Wall had one of the women depicted furnish and use the apartment as though she lived there. Wall photographed the apartment at several points in time before digitally recombining these photographs into the final anti-photograph.

Wall's anti-photographic practice has also taken him into the highly creative realm of staging scenes from literature such as his Odradek, Tàboritskà 8, Prague, 18 July 1994 [Museum of Modern Art, Frankfurt] which enacts a brief scene of a woman descending a staircase [once again the art historical reference is unavoidable, this time to a famous work by Marcel Duchamp], from Kafka’s story “The Cares of a Family Man”. The story is about "Odradek", a being who is part wooden, part living human, who remains hidden in the stairways of buildings. This work is also a reference to Wall's own work which also often focuses on invisible and unseen people (such as The Invisible Man (1999-2000), The Volunteer (1996), or Morning Cleaning (1999)).

An image such as Odradek is not a photograph as the writer understands it but rather more resembles a scene from cinema. Being captured by the gaze of the everyday object is here sacrificed to the incredible effort to seize the everyday object which is constructed like a film set to enact a script. This is another instance of Wall's powerful anti-photography — a practice that does not distinguish between the everyday world and the 
script, between the object in the world and the set design or between the object of photography and the object of the literary imagination. The result may be interesting, in the minds of some it may even be beautiful, there is no question it is art, but people should not call equate it with photography.

One of Wall's more well known and often reproduced images is Dead Troops Talk (a vision after an ambush of a Red Army patrol, near Moqor, 1986). Here people move beyond the cinematographic enactment of literature to a close encounter with cinema itself. This image has the look and feel of one from a popular horror movie. What it is however is Wall's effort to depict what he imagined as a dialogue among recently killed soldiers. Again, this anti-photograph is a meticulously arranged as any historical painting or scene from a film studio with actors, costumes and make up. The final image exists only as a virtual image as the soldiers are photographed individually and later put together in this digitalized montage.

Finally, Wall's The Flooded Grave (1998-2000, private collection), is interesting to the writer as an anti-photograph because it shows people an event that is not a single event in a moment that is not a single moment. Again they find Wall dreaming of photography as this image took almost two years to complete and was made from over 70 different images taken at two cemeteries and a set in Wall's studio. It is a digital montage which dreams of the singular event in its moment but it is the antithesis of the momentary image that is the photograph.

The camera has long troubled people because it records a world from which they are expelled by the photographic act itself. Every time they click our shutter and record an image, they remove ourselves one degree from the world they have photographed. This process of self-extermination weighs heavily and many, like Wall, respond to it by attempting to take control of the camera and its images. If Wall's images were photographs they would not seek control, but rather, surrender it as the photographic act must. It is the world that demands to be photographed, and the object that commands their attention, the photographer is merely part of the furniture in a pictorial space dominated by the object seizing them. A photographer is a conduit through which objects appear in photographs. Jeff Wall is a very fine artist but he is not a photographer because for him images result from a reversal of such photographic practice - in his images the objects perform for the subject - Wall”s images are like cinema, objects do not command Wall, Wall commands them. This is interesting, it is often thought provoking, but this kind of image making is not photography - indeed, it is in its opposite. It takes a certain amount of courage to do what Wall does - and it will take more for them to recognize it as something else other than photography. The solution is much more complex, subtle and poetic than common sense may allow.

What Wall's images do, and this is his real importance, is to show people the dis-ease they have with the camera - a dis-ease that mounts as people pass deeper into the era of the digital. There are many image takers and image makers (Wall being the later). Image making is not photography. Wall is a fabulous maker of images as Goddard is a fabulous maker of cinema, but Wall is not participating in photography understood as an object dominated endeavor. His images are art, but they are not photographs. Wall's images are an escape into subjectivity and aesthetics - a place where the photographer does all the work. The magic of photography however derives from the fact that it is the object which does (at least some of) the work (Baudrillard, 1996, p. 86). For a photograph to take place, the otherness of the object must remain intact. Wall”s images are not the kind which filters out the subject, and indeed, they impose the subjective vision over the object at every turn. As people subject themselves to increasing digitalization it is important that they recognize that its appeal to them is largely aesthetic. 
People can never photograph, nor can they appreciate photography, until they can allow themselves to understand the radical objectivity of the object — able to escape our subjective view - able to command their attention and focus. People like to think it is their subjects who discover the object but photography tells them something else entirely. Ironically it is a machine, the camera, that reminds them of the poetry of seeing and being seen.

\section{Conclusion}

Why do people in the art world insist on calling Jeff Wall's images photographs? The answer is of course that the art world has no interest in photography outside of, or before, aesthetics (which is precisely where my understanding of photography originates). Art once feared for its life against photography and it took over a century for the art world to execute the capture of photography. Wall's images are devoted, in practice and in method of display, to the end of photography. Wall's images can only be understood as "photography" by the terms of the official art world. Outside of that world Wall's images offer a literal "transparency" of the photograph as he wrests control over the image and its means of creation and display. This is a dilution of photography, just as his meticulously arranged subject matter is forced and controlled away from the object that which photography is most about — into a subject based imagery — an anti-photography.

Jeff Wall has addressed the ways his work does not fit into the "new orthodoxies" of the art world and people should recognize his courage to resist these powerful forces. However, they must also recognize that he is an integral part of an older and very well established orthodoxy in the art world that is attracted to photography by a need to control it and to subject it to aesthetics.

Dr. Gerry Coulter is full professor of Sociology at Bishop”s University in Sherbrooke, Quebec, Canada. Where his excellence in teaching has been recognized on numerous occasions including his university”s highest award for teaching: the William and Nancy Turner Prize. His research interests are in art, photography, and contemporary theory. He is founding editor of the International Journal of Baudrillard Studies. Dr. Coulter is also the author of two recent books - From the Ocean to the Desert — The Poetics of Radicality (2012) and Art After The Avant Garde (2014), both of them are from Intertheory Press, USA.

\section{References}

David Shapiro. (Interviewee) \& Jeff Wall. (Interviewer) (2001). Museo Magazine, Vol. 3. Retrieved from http://www.columbia.edu/cu/museo/3/jeffwall.htm

Jean Baudrillard. (1990). Fatal Strategies: Crystal Revenge. (p. 83). New York: Semiotext(e).

Jean Baudrillard. (1996). The Perfect Crime. (pp. 86-87). New York: Verso.

Jean Baudrillard. (1997). Art and Artefact. (p. 14). London: Sage Publications Ltd.

Jean Baudrillard. (2001). Impossible Exchange. (p. 17). London: Sage Publications Ltd.

Toni Ross. (2002). Art in the "Post-Medium" Era: Aesthetics and Conceptualism in the Art of Jeff Wall. The South Atlantic Quarterly, Vol. 101(3), 555-572. 